\title{
The Effect of Energy Density and Nb Content on the Microstructure and Mechanical Properties of Selective Laser Melted Ti-(10-30 wt.\%) Nb
}

\author{
James M. Borgman (D), Jing Wang, Lorenzo Zani, Paul P. Conway, and Carmen Torres-Sanchez
}

Submitted: 1 December 2020 / Revised: 22 July 2021 / Accepted: 3 September 2021 / Published online: 20 September 2021

\begin{abstract}
In this study, Ti-(0-30 wt.\%)Nb alloys developed from elemental powders were fabricated by the Selective Laser Melting (SLM) process. Compositional homogeneity, microstructure and mechanical performance were investigated as a function of energy density. The proportion of un-melted $\mathrm{Nb}$ particles and isolated pore count reduced with increasing energy density, while Ti allotropic content (i.e. $\alpha$, $\alpha$ " and $\beta$ ) varied with energy density due to in-situ alloying. Increasing the $\mathrm{Nb}$ content led to the stabilisation of the $\alpha$ " and $\beta$ phases. The mechanical properties were similar to those compositions manufactured using casting methods, without further post processing. The addition of $20 \mathrm{Nb}(\mathrm{wt} . \%)$ and using an energy density of $230 \mathrm{~J} / \mathrm{mm}^{3}$ resulted in a Young's Modulus of 65.2 $\pm 1.8 \mathrm{GPa}$, a yield strength of $769 \pm 36 \mathrm{MPa}$ and a microstructure of predominantly $\alpha$ " martensite. This strength to stiffness ratio $(33 \%$ higher than Ti-10Nb and $22 \%$ higher than Ti-30Nb), is attributed to in-situ alloying that promotes solid solution strengthening and homogenisation. These alloys are strong contenders as materials suitable for implantable load-bearing orthopaedic applications.
\end{abstract}

Keywords additive manufacturing, biomedical, Titanium, mechanical testing

\section{Introduction}

Titanium and its alloys have characteristics, such as low density, corrosion resistance and non-toxicity for in vivo applications, making them ideal materials for use in orthopaedics and tissue engineering. However, titanium has a larger Young's Modulus (100 GPa) compared to cortical bone (10-30 GPa) (Ref 1). A mismatch that can lead to stress-shielding and osteopenia (Ref 2). It is desirable to lower the Young's Modulus of the implant material, close to that of the host tissue, i.e., bone. A proposed approach is to alloy titanium (Ti) with elements, such as niobium $(\mathrm{Nb})$, molybdenum (Mo) or tantalum (Ta). These alloying elements, known as isomorphous $\beta$ stabilisers, prevent the formation upon cooling of the hexagonal $\alpha$ phase, allowing the retention of the high temperature $\beta$ phase. The presence of the $\beta$ phase at room temperature has been found to lower Young's Modulus, in comparison to the $\alpha$ phase

This invited article is part of a special topical focus in the Journal of Materials Engineering and Performance on Additive Manufacturing. The issue was organized by Dr. William Frazier, Pilgrim Consulting, LLC; Mr. Rick Russell, NASA; Dr. Yan Lu, NIST; Dr. Brandon D. Ribic, America Makes; and Caroline Vail, NSWC Carderock.

James M. Borgman, Jing Wang, Lorenzo Zani, Paul P. Conway, and Carmen Torres-Sanchez, Multifunctional Materials Manufacturing Laboratory, Wolfson School of Mechanical, Electrical and Manufacturing Engineering, Loughborough University, Ashby Road, Loughborough, Leicestershire LE11 3TU, UK. Contact e-mail: j.m.borgman@lboro.ac.uk. present in pure titanium (Ref 3,4$)$. The addition of these $\beta$ stabilisers can also lead to the presence of additional phases, including the orthorhombic $\alpha$ " martensitic phase and the interstitial $\omega$ phase. These phases alter the mechanical properties, with $\alpha$ " leading to a reduction of the Modulus compared with the $\alpha$ phase, and the $\omega$ phase leading to an increase (Ref $5)$. $\mathrm{Nb}$ is a $\beta$ stabilising element with lower cyto-toxicity, in comparison with other $\beta$ stabilisers, such Mo and Fe (Ref 4,6). Ti-Nb alloys have been found to contain high strength and low Young's Modulus, making them promising for orthopaedic implant applications (Ref 4,7,8).

Selective Laser Melting (SLM), which uses a laser to melt powder in layers to build the required part, can manufacture customised orthopaedic implants of complex geometries, with lowered investment cost and reduced machine time compared to traditional processes such as casting (Ref 9,10). The application of this process has been dominated by industrially attractive alloys, such as Ti-6Al- $4 \mathrm{~V}$, a $\alpha+\beta$ phase alloy, with few investigating $\beta$ stabilised titanium alloys, such as Ti-Nb alloys (Ref 11-13).

The limited adoption of Ti-Nb alloys is in part due to the high cost of the pre-alloyed powders, and the difficulty in achieving "in-situ alloying", i.e. when the laser beam not only melts but also homogenises elemental powders in the melt pool (Ref 14,15). Attempts have been made to use in-situ alloying to improve the mechanical properties, including adding yttriastabilised zirconia to Ti-6Al-4V to increase hardness, rhenium to titanium to improve the corrosive properties and Mo to Ti$6 \mathrm{Al}-4 \mathrm{~V}$ to improve strength (Ref 16-18). Owing to the complex nature of the SLM thermal profile, as well as differences in fusion temperature of added alloying elements, achieving compositional homogenisation remains largely unresolved. Several studies have investigated the in-situ alloying of $\mathrm{Ti}$ with $\beta$-stabilising elements (Ref 14,16,19-21). Fischer et al. showed that increments in energy density improved homogenisation of in-situ alloyed Ti-26Nb (at.\%) (Ref 22). Similar 
results have been reported by Chen et al. using a mixture of Ti$37 \mathrm{Nb}-6 \mathrm{Sn}$ (wt.\%) from elemental powders (Ref 23). In terms of $\mathrm{Nb}$ content, Wang et al. suggests that the quantity of $\mathrm{Nb}$ within the alloy affects its homogenisation, with increased $\mathrm{Nb}$ content leading to an increased fraction of un-melted $\mathrm{Nb}$ (Ref 24). However, as shown in Fig. 1, little work has focused on Ti-Nb alloys, especially at compositions, where $\alpha$ and $\alpha "$ are expected (Ref 7,22-29).

To the best of the author's knowledge, no study has systematically compared the effect of $\mathrm{Nb}$ content with energy density. Therefore, this present work focuses on the influence of energy density and $\mathrm{Nb}$ content to produce $\mathrm{Ti}-\mathrm{Nb}$ alloys (10, 20 and $30 \mathrm{Nb}(\mathrm{wt} . \%))$. These compositions were chosen as exemplars of different allotropic phases; i.e., $\mathrm{Ti}-10 \mathrm{Nb}$ is expected to display a predominant $\alpha^{\prime}$ phase, Ti-20Nb containing the $\alpha$ " phase and Ti-30Nb expected to contain $\alpha$ " $+\beta$ phases. The chosen compositions are yet to be explored, as shown in Fig. 1. The phases, microstructural evolution, homogeneity, and mechanical properties of these alloys were investigated with respect to those produced using conventional methods, such as vacuum cast re-melting.

\section{Materials and Methodology}

\subsection{Material Preparation}

Gas atomised CP-Ti powder (Carpenter Additive Ltd, USA, $99.5 \%, \mathrm{D} 50=34 \mu \mathrm{m})$, and mechanically crushed $\mathrm{Nb}$ powder (Alfa Aesar, UK, 99.8\%, <45 $\mu \mathrm{m}$ ), were mixed to the required composition (i.e. 0 (referred to as CP-Ti), 10, 20 and $30 \mathrm{wt} \%$ $\mathrm{Nb}$ ). All compositions are provided in wt.\%, unless otherwise stated. Mixing was performed on a PM100 (Retsch, Germany), using a ball to powder mass ratio of 2:1 at 100 RPM for 1 hour. The morphology and size of the powder after mixing, was observed using a Scanning Election Microscope (7800, JEOL, Japan). As shown in Fig. 2, morphology and powder characteristics are consistent with the pre-mixed powder, and no variation was observed as a result of the mixing process. In addition, the $\mathrm{Nb}$ particles were found to be evenly distributed in the Ti powder. The average powder size was 34.0, 32.3, 30.1, $29.6 \mu \mathrm{m}$ for $\mathrm{CP} \mathrm{Ti}, \mathrm{Ti}-10 \mathrm{Nb}, \mathrm{Ti}-20 \mathrm{Nb}$ and $\mathrm{Ti}-30 \mathrm{Nb}$, respectively. All compositions had good flowability and printing characteristics, with Ti-30 Nb (containing the highest fraction of non-spherical $\mathrm{Nb}$ particles), having a powder density $45 \%$ and high circularity (0.87), suitable for the SLM process.

\subsection{In-situ Alloying of Ti-Nb Alloy by SLM}

The SLM process was conducted using a TruPrint 1000 LMF (Trumpf, Germany), equipped with a $200 \mathrm{~W} \mathrm{Nd:YAG}$ solid-state laser with a spot size of $55 \mu \mathrm{m}$. Processing was completed within an argon atmosphere to an oxygen content below $100 \mathrm{ppm}$ to prevent oxidation.

The laser scanning parameters were chosen to control the volumetric energy density supplied to the fabricated part. The Volumetric Energy Density (VED) was calculated using Eq. 1.

$\operatorname{VED}\left(\mathrm{J} / \mathrm{mm}^{3}\right)=\frac{P}{V \times h \times t}$

Where $\mathrm{P}=$ laser power $(\mathrm{W}), \mathrm{V}=$ scanning speed $(\mathrm{mm} / \mathrm{s}), \mathrm{h}=$ hatch distance $(\mathrm{mm}), \mathrm{t}=$ layer thickness $(\mathrm{mm})$.

Based on initial evaluation of potential parameters available, three different values of energy density were chosen $\left(50 \mathrm{~J} / \mathrm{mm}^{3}\right.$, $110 \mathrm{~J} / \mathrm{mm}^{3}$ and $230 \mathrm{~J} / \mathrm{mm}^{3}$ ). These energy densities were chosen based on the maximum energy densities achievable within the limits of the machine (i.e. $230 \mathrm{~J} / \mathrm{mm}^{3}$ ), and the lowest energy

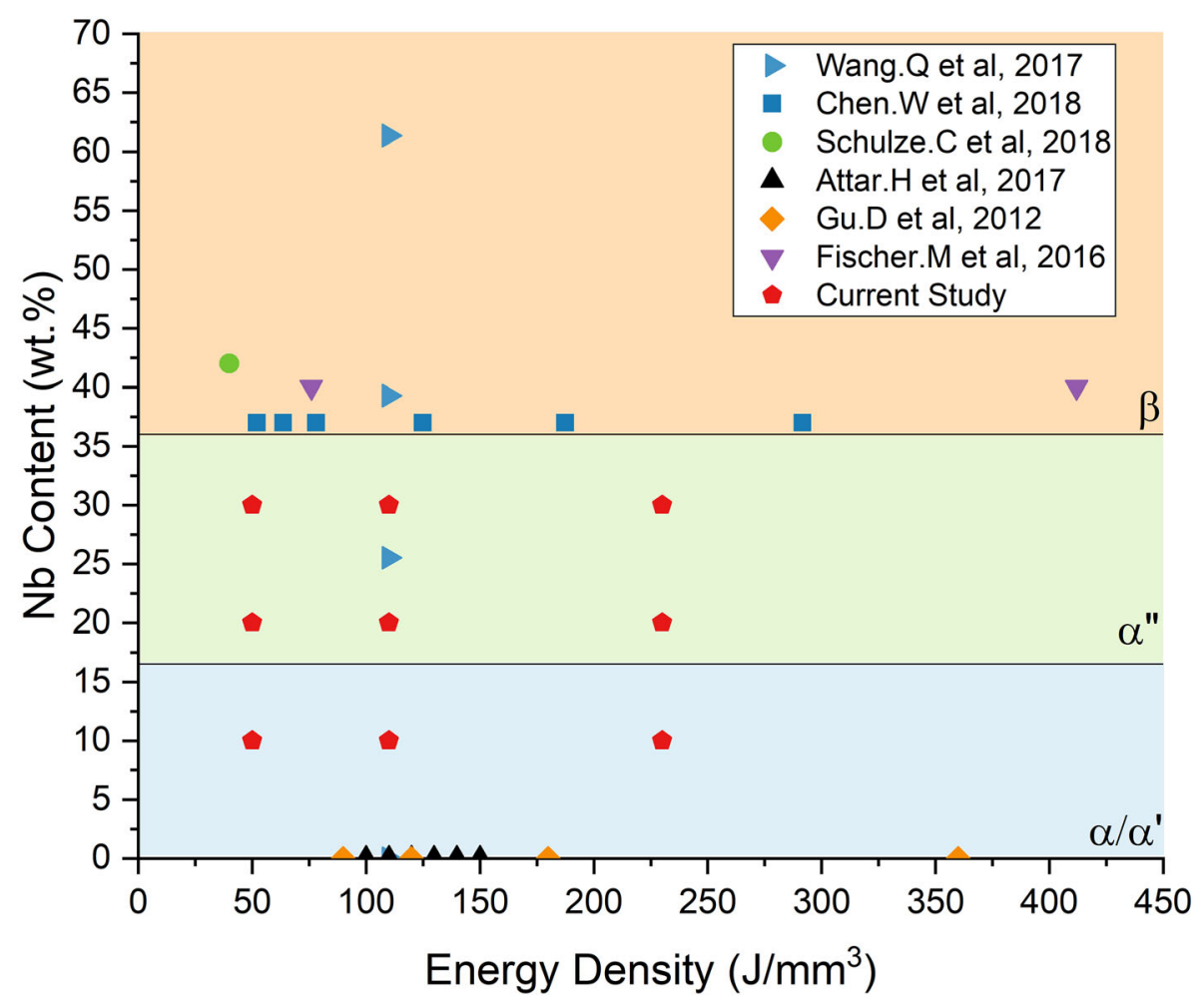

Fig. 1 Energy Density vs $\mathrm{Nb}$ (wt.\%) examined in literature, as well as the predicted phase expected based on Mo equivalence (Ref 7,22-29) 

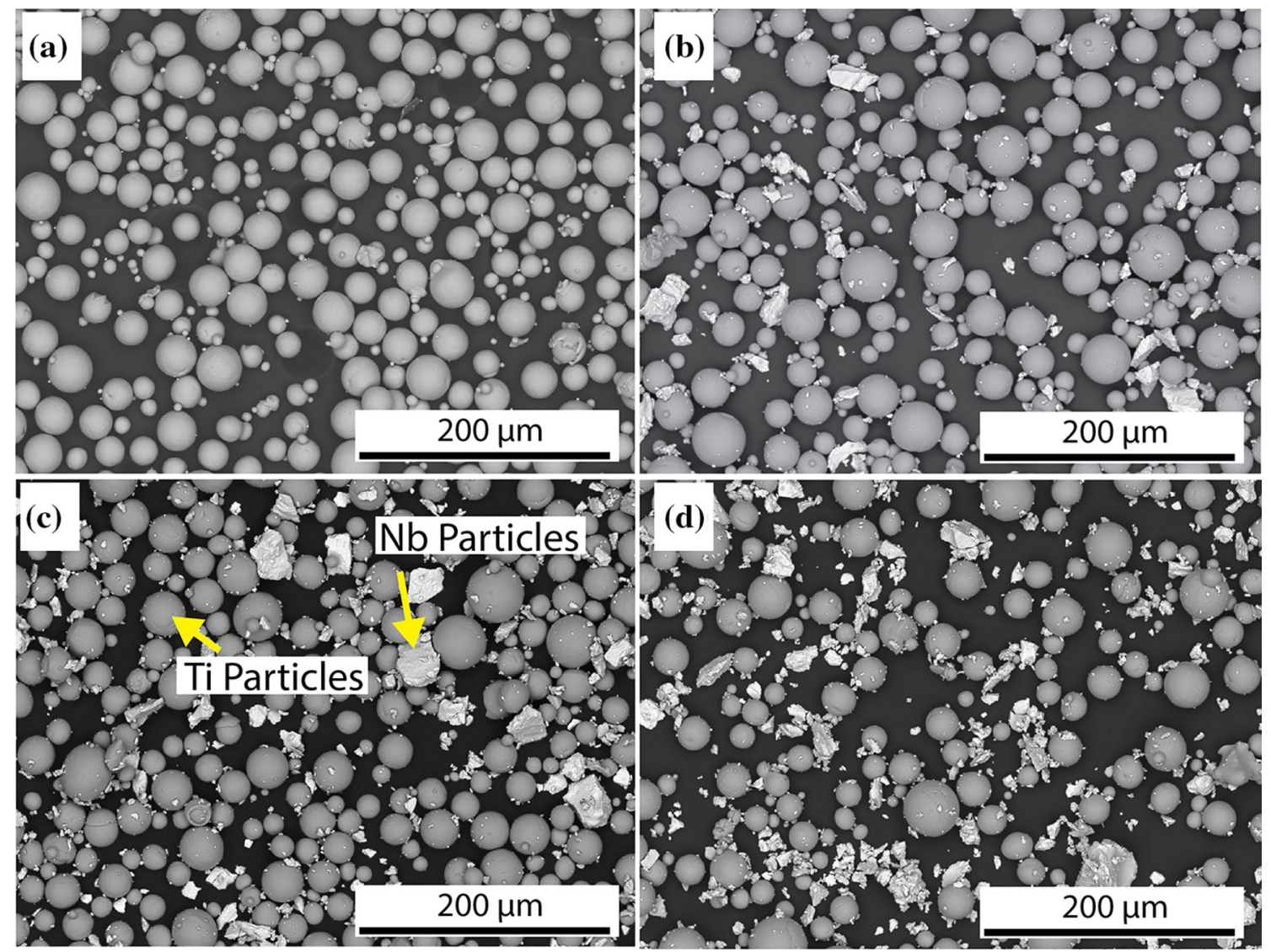

Fig. 2 SEM micrographs of CP-Ti (a), Ti-10Nb (b), Ti-20Nb (c), and Ti-30Nb (d) powder feedstock after mixing

Table 1 Chosen laser scanning parameters

\begin{tabular}{|c|c|c|c|c|c|}
\hline $\begin{array}{l}\text { Volumetric Energy } \\
\text { Density, } \mathrm{J} / \mathrm{mm}^{3}\end{array}$ & $\begin{array}{c}\text { Laser } \\
\text { power, } \mathbf{W}\end{array}$ & $\begin{array}{c}\text { Hatch } \\
\text { distance, } \mu \mathrm{m}\end{array}$ & $\begin{array}{c}\text { Layer } \\
\text { thickness, } \mu \mathrm{m}\end{array}$ & $\begin{array}{c}\text { Scanning } \\
\text { speed, } \mathbf{m m} / \mathbf{s}\end{array}$ & Scanning strategy \\
\hline 50 & 140 & 110 & 30 & 848 & bi-directional raster with $90^{\circ}$ offset between layers \\
\hline 110 & 140 & 110 & 30 & 386 & bi-directional raster with $90^{\circ}$ offset between layers \\
\hline 230 & 140 & 110 & 30 & 186 & bi-directional raster with $90^{\circ}$ offset between layers \\
\hline
\end{tabular}

density able to successfully fabricate the required part (i.e. $50 \mathrm{~J} /$ $\mathrm{mm}^{3}$ ). $110 \mathrm{~J} / \mathrm{mm}^{3}$ was chosen as it is recommended manufacturers value for $\mathrm{CP}-\mathrm{Ti}$, being $60 \mathrm{~J} / \mathrm{mm}^{3}$ higher than the lowest value and $120 \mathrm{~J} / \mathrm{mm}^{3}$ lower than the higher energy density achievable. Scanning speed was chosen as the parameter of interest, as it allowed greater flexibility compared to the other parameters in the energy density equation. The scanning speed was altered to achieve the required energy density, while other parameters were maintained as shown in Table 1. For each composition and energy density, two cubic samples $(7 \times 7 \times 7 \mathrm{~mm})$ were fabricated for microstructural analysis, and three cylindrical samples (6 mm diameter x $12 \mathrm{~mm}$ height) were fabricated for mechanical testing. After fabrication, the samples were cut from a build plate along the $x-y$ plane with the use of a high-speed saw (IsoMet High Speed Pro, Buehler, Germany) fitted with a diamond-coated blade (IsoMet Blade, 15HC - 4in, Buehler, Germany). For metallurgical examination, samples were ground with P400 grit SiC abrasive paper, followed by polishing with 9 $\mu \mathrm{m}$ diamond suspension, and 0.02-0.6 $\mu \mathrm{m}$ colloidal silica. Grinding and polishing processes were performed using an automated polishing machine (Automet 250, Buehler, USA).

\subsection{Microstructural and Homogeneity Analysis}

Homogeneity characterisation was ascertained by calculating the area fraction of un-melted $\mathrm{Nb}$ particles within the entire cross-section, obtained from a Scanning Electron Microscope (SEM, 7800, JEOL, Japan). Further SEM micrographs were on chemically etched surfaces (Kroll's reagent, vol. 91\% $\mathrm{H}_{2} \mathrm{O} 6 \%$ $\mathrm{HNO}_{3}, 3 \% \mathrm{HF}$, exposed for 15 seconds) to reveal microstructural features. Optical micrographs (Zeiss Primotech Materials Microscope, USA) were used to measure void content. The area fraction of the voids was calculated from optical micrographs, using MATLAB software (MATLAB ver. R2018b, The MathWorks, inc., USA). The plane of analysis for optical and SEM imaging was offset by $3 \mathrm{~mm}$ from the top surface in the build 
direction, to avoid transitional effects present in the outermost top layers.

\subsection{X-Ray Diffraction}

The phase identification was performed using an $\mathrm{x}$-ray Diffractometer (D2, Bruker, USA) with a $\mathrm{Cu}$ source, operating with a voltage of $30 \mathrm{kV}$, and an electron current of $10 \mathrm{~mA}$. The peaks were measured from a $2 \theta$ angle of $30^{\circ}$ to $80^{\circ}$, with a step of $0.2^{\circ}$.

\subsection{Differential Scanning Calorimetry}

Differential Scanning Calorimetry (DSC) was performed to assess the phases present in the sample and measure the transformation temperature to give an understanding of the $\beta$ stabilisation of the fabricated alloy. The DSC measurements were performed on a Shimadzu DSC60 (Kyoto, Japan), with a cooling/heating rate of $10{ }^{\circ} \mathrm{C}$, from an initial temperature of 40 ${ }^{\circ} \mathrm{C}$ up to a max temperature of $570{ }^{\circ} \mathrm{C}$. The second heating/cooling cycle was performed to assess the decomposition of metastable phases within the alloy. The machine was continuously purged with Argon gas, at a rate of $100 \mathrm{ml} / \mathrm{min}$. A baseline scan was performed without any samples present, and used to remove any noise from the scan. The samples used were cut to a mass between $60-80 \mathrm{mg}$, and cleaned in isopropyl before use.

\subsection{Mechanical Testing}

The samples were prepared, according to the ASTM E9 standard, having a length-diameter ratio equal to 2 (Ref 30$)$. Top and bottom faces were ground with $\mathrm{P} 800$ grit $\mathrm{SiC}$ paper to ensure they were flat and parallel. All compression specimens were fabricated with dimensions $12 \mathrm{~mm}$ in length and $6 \mathrm{~mm}$ in diameter. Compression testing was performed on an Instron universal testing machine (3369, Instron, UK, $20 \mathrm{kN})$, with a constant strain rate of $0.005 \mathrm{~s}^{-1}$. The Young's Modulus was obtained from the slope of the elastic region formed, when plotting stress vs strain. An extensometer (2601, Instron, UK) was attached to a mechanical testing rig to accurately assess the strain and calibrated before use to the manufacturer's recommendation. Three test samples of each parameter set were assessed, with each sample being loaded in the elastic region 5 times to ensure repeatability. Finally, samples were loaded to plastic deformation to obtain the yield strength. The yield strength was calculated using the $0.2 \%$ strain-offset method.

\section{Results and Discussion}

\subsection{Phase Analysis}

Figures 3, 4, 5 and 6 exhibits the XRD scans of the asfabricated alloy composition at the chosen energy densities. The CP-Ti (Fig. 3) and Ti-10Nb (Fig. 4) alloys all displayed peaks associated with the hcp $\alpha$ (or hcp $\alpha$, given that both display the same lattice parameters) phase. When the $\mathrm{Nb}$ content was increased to $20 \%$ and above, martensitic orthorhombic $\alpha$ " was the predominant phase present in the alloy (Fig. 5). This phase is developed from the distortions of the Ti lattice, due to the introduction of $\mathrm{Nb}$ atoms, and is often found in $\mathrm{Ti}-\mathrm{Nb}$ alloys with $>13 \mathrm{Nb}$ (Ref 31). In addition to the $\alpha$ " phase, other peaks present are associated with the cubic $\beta$ phase as indicated. This phase is unexpected in a fully homogenised alloy at Ti-20Nb, with the only phase expected being $\alpha "$ (Ref 31$)$. Therefore, the suspected $\beta$ phase peaks can be linked to locally enriched $\mathrm{Nb}$ regions or un-melted $\mathrm{Nb}$ particles in the Ti-Nb matrix. The presence of both phases $(\beta$ and $\alpha$ "), is an indication that the alloy has not been fully homogenised by the SLM process. However, with increments in the energy density, the intensity of the peaks associated with the $\beta$ - $\mathrm{Nb}$ phase decrease. This highlights the impact of energy density in increasing the homogenisation of the alloy, and reducing the presence of un-melted $\mathrm{Nb}$ particles. Ti-30Nb (Fig. 6) also exhibited peaks linked to $\alpha$ " phase and $\beta$ phases. However, the increased $\mathrm{Nb}$ content led to an increased peak intensity of the $\beta$ phase, and therefore an indication of a further $\beta$ stabilised alloy.

All compositions displayed a growth in the preferred crystallographic texture with increasing energy density. The $\mathrm{CP}-\mathrm{Ti}$ and $\mathrm{Ti}-10 \mathrm{Nb}$ alloys showed increased intensities in peaks, associated with the $\alpha(102)$ and $\alpha(110)$, and a corresponding decrease in $\alpha(101)$ peak. On the contrary, Ti-20Nb and Ti-30Nb alloys exhibited growth in the $\alpha$ " $(022)$ and $\beta(200)$ orientations, as the energy density increased. It is hypothesised that this trend is a result of the re-melting of applied layers with the subsequent laser scans during the SLM process, resulting in elongated grain growth along the thermal gradient. With higher energy density the heat penetration increased, creating a large thermal gradient in the build direction, and increasing crystallographic alignment in this direction. This can be corroborated by the enlarged $\beta(200)$ peak in the Ti-20Nb and Ti-30Nb alloys, suggesting the $\beta$ prior grains are orientated in the $\{001\}$ $<100>$ direction, corresponding to the build direction (Ref $23)$. The increase in the $\alpha$ "(022) peak in the Ti-20Nb alloy can be explained by the orthorhombic transformation, undergone during rapid cooling from the $\beta(200)$ textured prior $\beta$ grains to $\alpha$ " $(022)$ orientation, using the lattice correspondence $\{001\}_{\beta} \rightarrow$ $1 / 2\{011\}_{\alpha^{\prime \prime}}$ (Ref 32). A comparison between the relative intensities of the peaks of $\mathrm{Ti}-20 \mathrm{Nb}$ and $\mathrm{Ti}-30 \mathrm{Nb}$ alloys manufactured at $230 \mathrm{~J} / \mathrm{mm}^{3}$ showed increased $\mathrm{Nb}$ content led to a reduction in the $\alpha$ "(022) peak, and an increase in the $\beta(200)$ peak. This change in relative intensity indicates a link between increased $\mathrm{Nb}$ concentration and increased $\beta$ stabilisation, which leads to the suppression of the martensitic $(\beta \rightarrow \alpha$ ") transformation.

\subsection{Void Content}

The formation of voids was found to be correlated to the $\mathrm{Nb}$ content and the energy density used (Fig. 7). At $50 \mathrm{~J} / \mathrm{mm}^{3}$ increasing the $\mathrm{Nb}$ content was found to lead to an increase in the area fraction of voids, from $0.045 \%$ in $\mathrm{Ti}-10 \mathrm{Nb}$ through $0.6 \%$ in $\mathrm{Ti}-20 \mathrm{Nb}$ to $1.67 \%$ in $\mathrm{Ti}-30 \mathrm{Nb}$. This suggests that at the low energy density, the presence of isolated pores is dependent on the $\mathrm{Nb}$ content. However, at $230 \mathrm{~J} / \mathrm{mm}^{3}$ all alloys displayed similar levels of porosity, rendering the phenomenon independent of $\mathrm{Nb}$ content with sufficient energy density. The increase in the area fraction of void with the increasing $\mathrm{Nb}$ content can be correlated to the higher melting temperature of $\mathrm{Nb}$ (2447 $\left.{ }^{\circ} \mathrm{C}\right)$, compared with $\mathrm{Ti}\left(1668{ }^{\circ} \mathrm{C}\right)$. Therefore, at the lower energy density, the energy supplied to the powder appeared insufficient for the complete melting of $\mathrm{Nb}$, resulting in a lack of fusion between the $\mathrm{Ti}$ and $\mathrm{Nb}$ particles and the presence of isolated pores. There were no pores or cracks linked to 


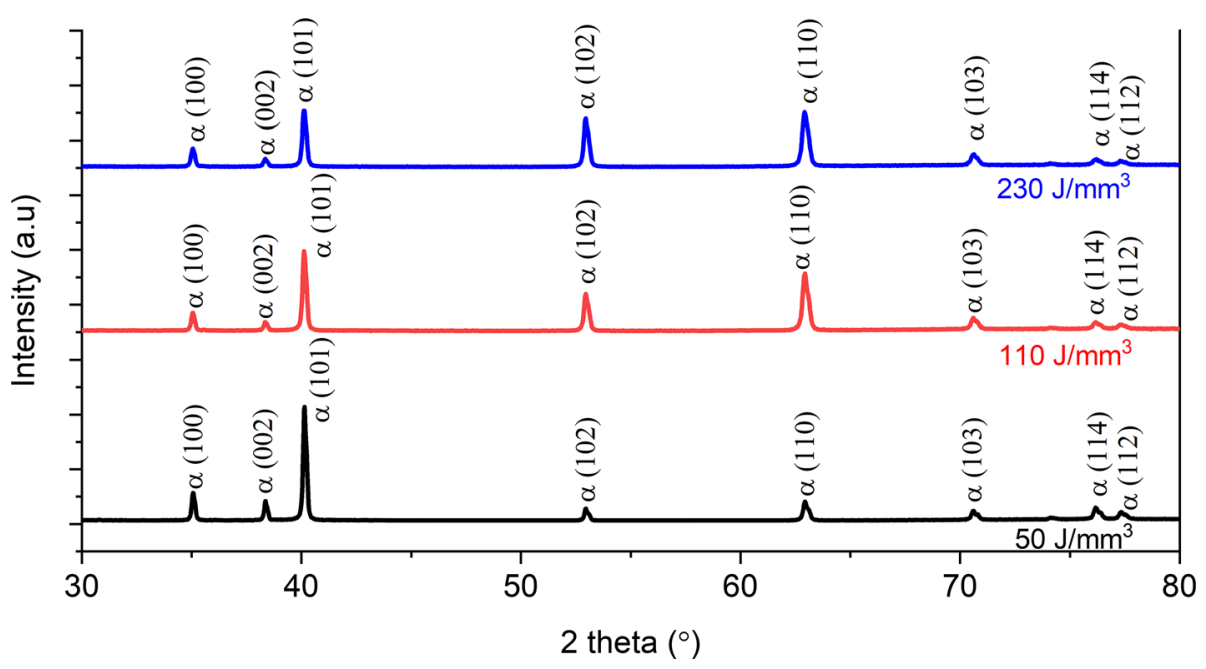

Fig. 3 XRD patterns of CP-Ti, as-fabricated as a function of energy densities

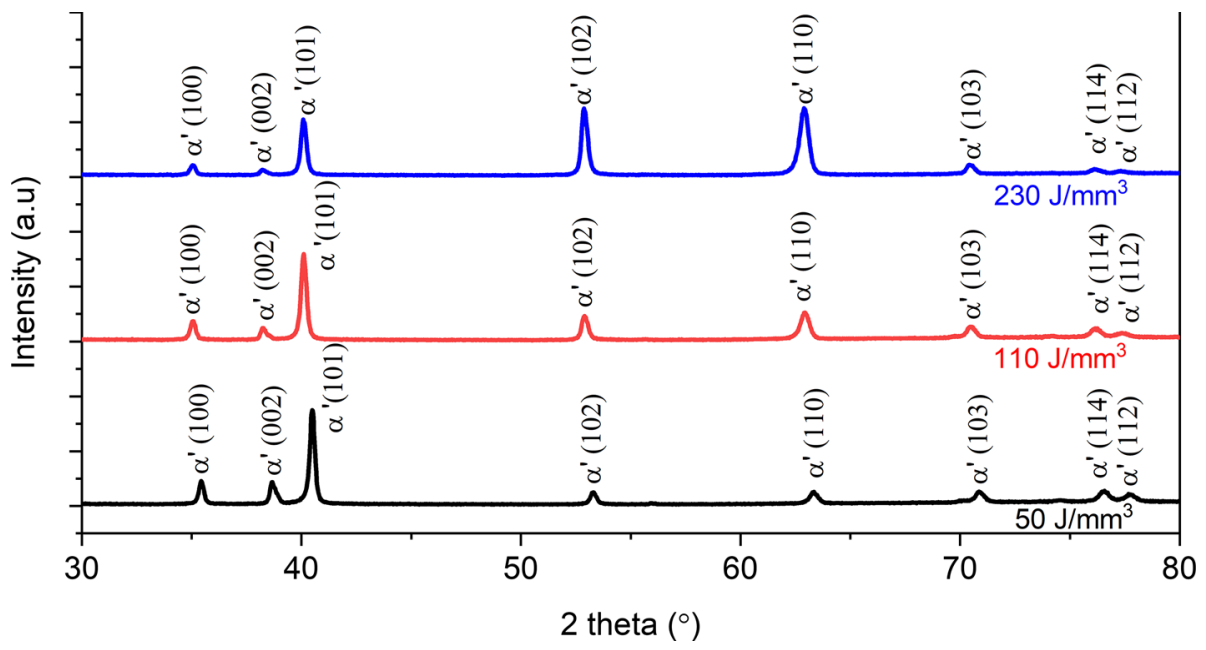

Fig. 4 XRD patterns of Ti-10Nb alloys, as-fabricated as a function of energy densities

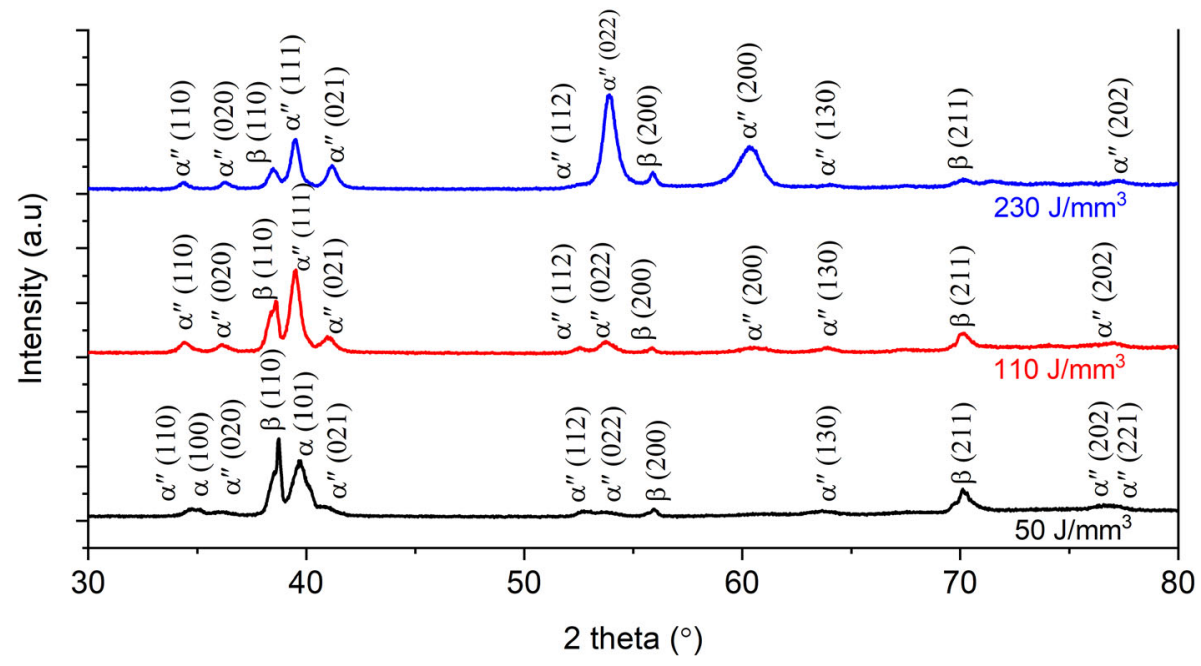

Fig. 5 XRD patterns of Ti-20Nb alloys, as-fabricated as a function of energy densities 


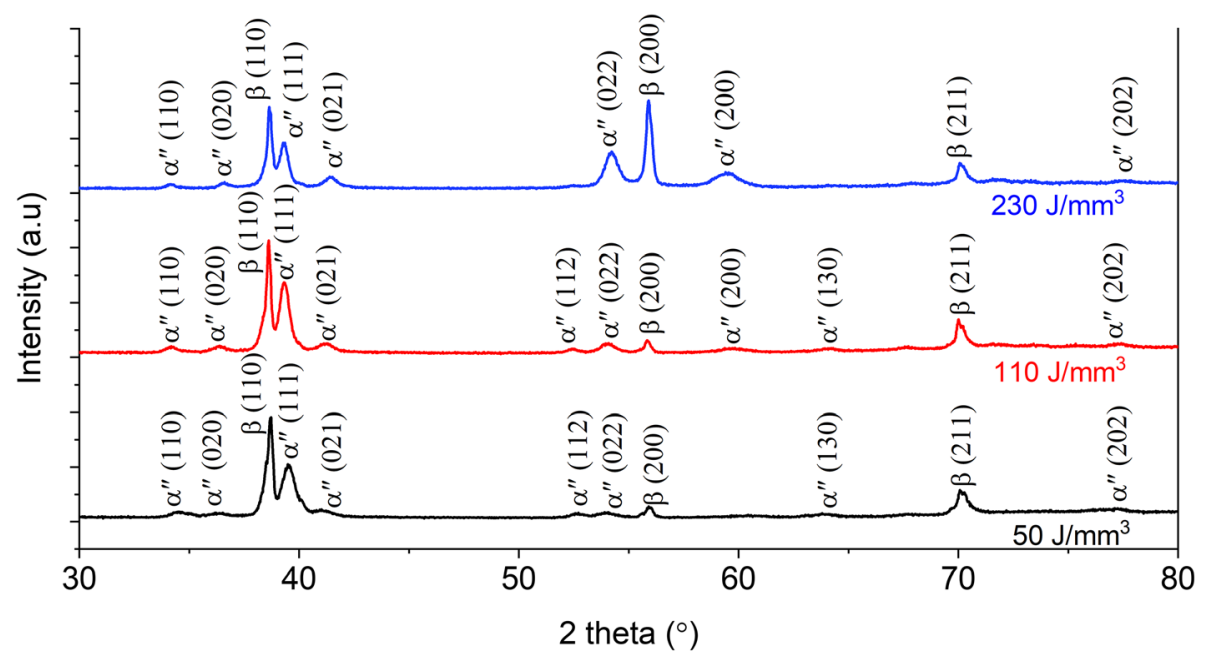

Fig. 6 XRD patterns of Ti-30Nb alloys, as-fabricated as a function of energy densities

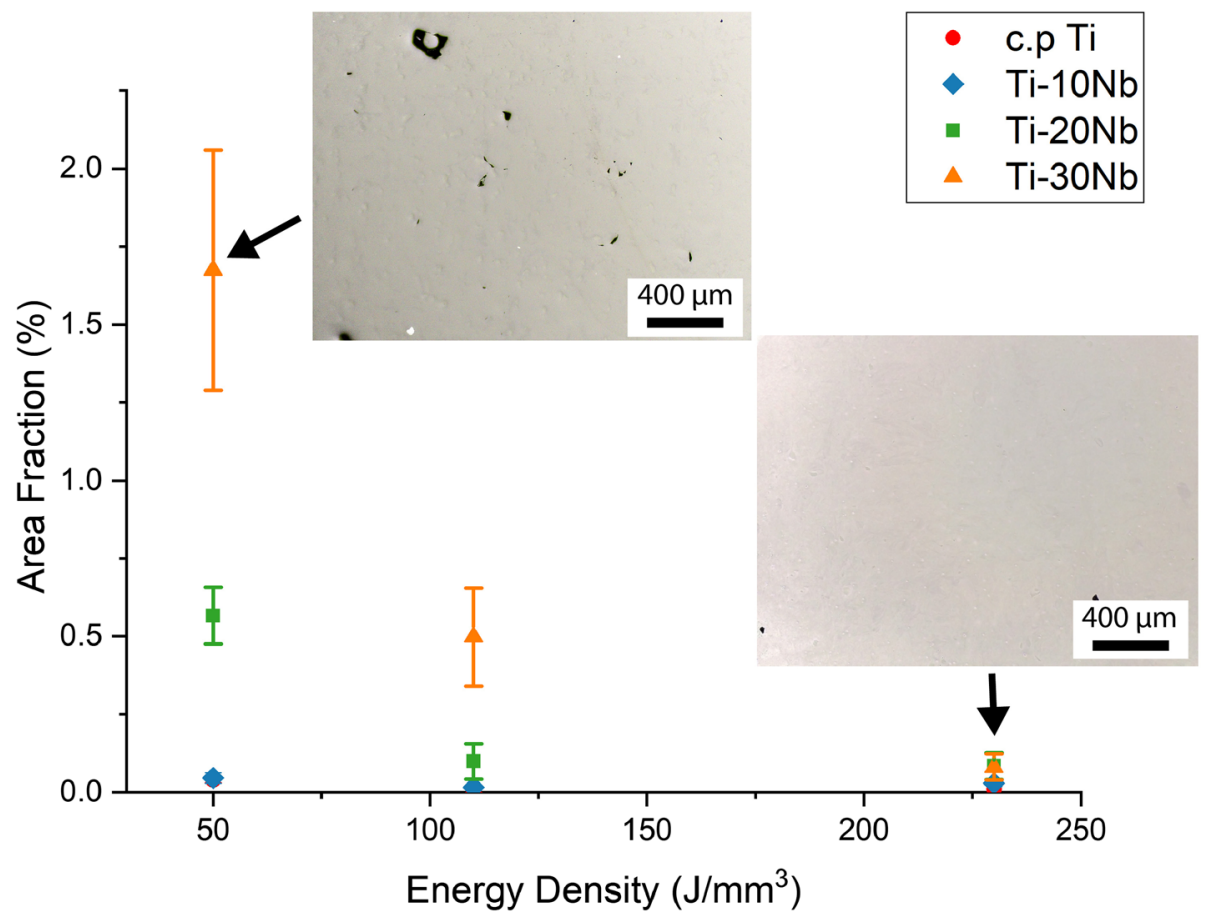

Fig. 7 Comparison in area fraction of voids with energy density and niobium (Nb) content (inset: optical micrographs of cross-sectional surface of the Ti-30Nb alloy at indicated energy densities)

excessive energy and gas entrapment found in any of the samples.

\subsection{Un-Melted Nb Particles}

Figure 8 shows the measured un-melted $\mathrm{Nb}$ area fraction, normalised against the added $\mathrm{Nb}$ content, of the $\mathrm{Ti}-\mathrm{Nb}$ alloys fabricated in this study, and the values are provided in Table 2. The inset micrographs show the chemical inhomogeneity present, depicting colour contrast as a result of the elemental atomic contrast, i.e. lighter areas linked to increased $\mathrm{Nb}$ content, and darker areas having a higher Ti content, and the white particles visible being the un-melted $\mathrm{Nb}$ particles. The presence of the un-melted $\mathrm{Nb}$ particles in the melt pool suggest that the temperature in the melt-pool is insufficient to melt some of the larger $\mathrm{Nb}$ particles, which is exacerbated at lower energy densities. As shown, the area fraction of un-melted $\mathrm{Nb}$ particles is linked to the energy density used, as with increasing energy density, the fraction of un-melted $\mathrm{Nb}$ particles decreases at all $\mathrm{Nb}$ contents. Increasing the added $\mathrm{Nb}$ content also increased in the un-melted fraction, with $\mathrm{Ti}-30 \mathrm{Nb}$ displaying the highest ratio, compared with $\mathrm{Ti}-20 \mathrm{Nb}$ and $\mathrm{Ti}-10 \mathrm{Nb}$. It is likely due to the increased added $\mathrm{Nb}$ content, and therefore, the increased heat of fusion in the melt pool (Ref 33).

\subsection{Microstructural Analysis}

For the Ti-(10-30) Nb alloys, the samples fabricated at 50 and $110 \mathrm{~J} / \mathrm{mm}^{3}$ displayed large variation in composition due to the elemental inhomogeneity, resulting in no clear and pre- 


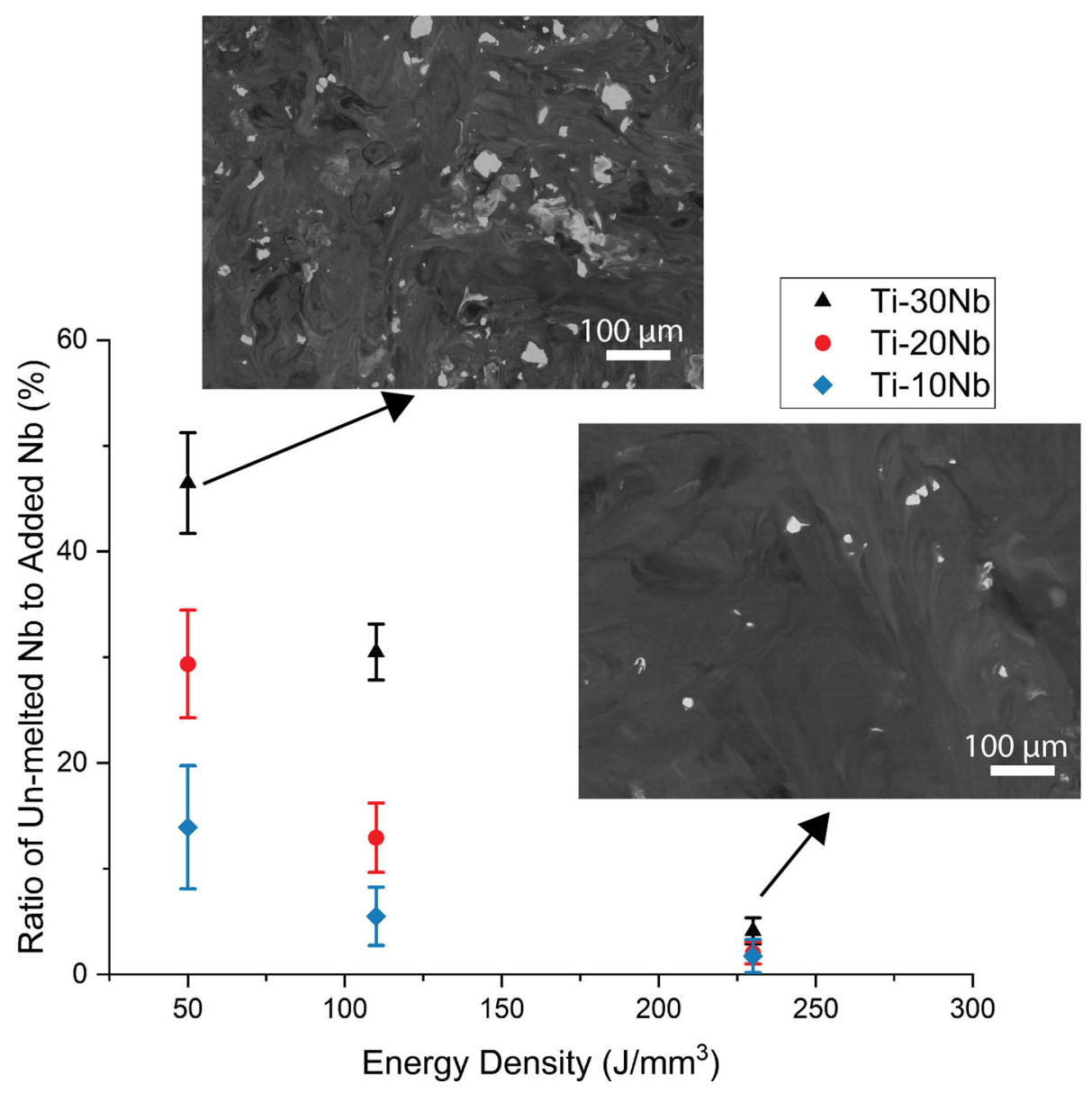

Fig. 8 Comparison in area fraction of un-melted $\mathrm{Nb}$ particles to added $\mathrm{Nb}$ content with energy density and niobium ( $\mathrm{Nb}$ ) content (inset: SEM micrographs of cross-sectional surface of the Ti-30Nb alloy at indicated energy densities)

Table 2 Area fraction of un-melted $\mathrm{Nb}$ particles to added $\mathrm{Nb}$ content with energy density and niobium (Nb) content

\begin{tabular}{lrrr}
\hline & \multicolumn{3}{c}{ Area fraction of un-melted Nb particles to added Nb content (\% \pm SD) } \\
\cline { 2 - 4 } & Ti-10Nb & Ti-20Nb & Ti-30Nb \\
\hline $50 \mathrm{~J} / \mathrm{mm}^{3}$ & $13.9 \pm 5.8$ & $29.6 \pm 5.1$ & $46.5 \pm 4.8$ \\
$110 \mathrm{~J} / \mathrm{mm}^{3}$ & $5.5 \pm 2.8$ & $12.9 \pm 3.3$ & $30.5 \pm 2.7$ \\
$230 \mathrm{~J} / \mathrm{mm}^{3}$ & $1.7 \pm 1.6$ & $2.0 \pm 1.1$ & $4.1 \pm 1.2$ \\
\hline
\end{tabular}

dominate microstructure. However, at the highest energy density $\left(230 \mathrm{~J} / \mathrm{mm}^{3}\right)$ a more homogenous microstructure was present. SEM (backscatter) micrographs of the etched microstructure of the alloys fabricated at this energy density are displayed in Fig. 9. At the highest energy density, the Ti$10 \mathrm{Nb}$ alloy (Figs. 9a-b) predominantly displayed a Widmanstätten $\alpha$ microstructure, similar to cast alloys of the same composition (Ref 31$)$. The Ti-20Nb alloy displayed a martensite $\alpha$ " microstructure with evident un-melted $\mathrm{Nb}$ particles. Melt pool boundaries and cellular structures were also present. Within the bulk sample (Figs. 9c-d), away from un-melted $\mathrm{Nb}$ particles, the $\alpha$ " martensite is present, and propagating from the edges of the prior $\beta$ grains. In addition to the primary martensite needles, in the range of $10 \mu \mathrm{m}$ in length (Fig. 9d), small needles are present orientated perpendicular to the primary needles. This morphology was described previously by Yang et al. (Ref
34) in the $\alpha$ phase of Ti-6Al-4V, who classified the martensitic needles into size categories (i.e. primary, secondary, tertiary etc) with decreasing size. This microstructure, not present in traditional manufactured alloys, is the result of the rapid heating and cooling of previously deposited layers. It is proposed that primary needles were formed in the initial heating cycles, with the subsequent heating cycles, forming the secondary, tertiary needles and the growth of the subsequent needles, being constrained by the presence of previous needles. This microstructure results in an increased density of dislocations, which impedes movements of the dislocations, and is the most plausible reason to explain the increased strength and reduced ductility present in the Ti-20Nb alloy, fabricated at 230 $\mathrm{J} / \mathrm{mm}^{3}$

The Ti-30Nb alloy (Fig. 9e-f) showed a primarily cellular $\beta$ microstructure, with the presence of martensitic $\alpha$ " phase also 

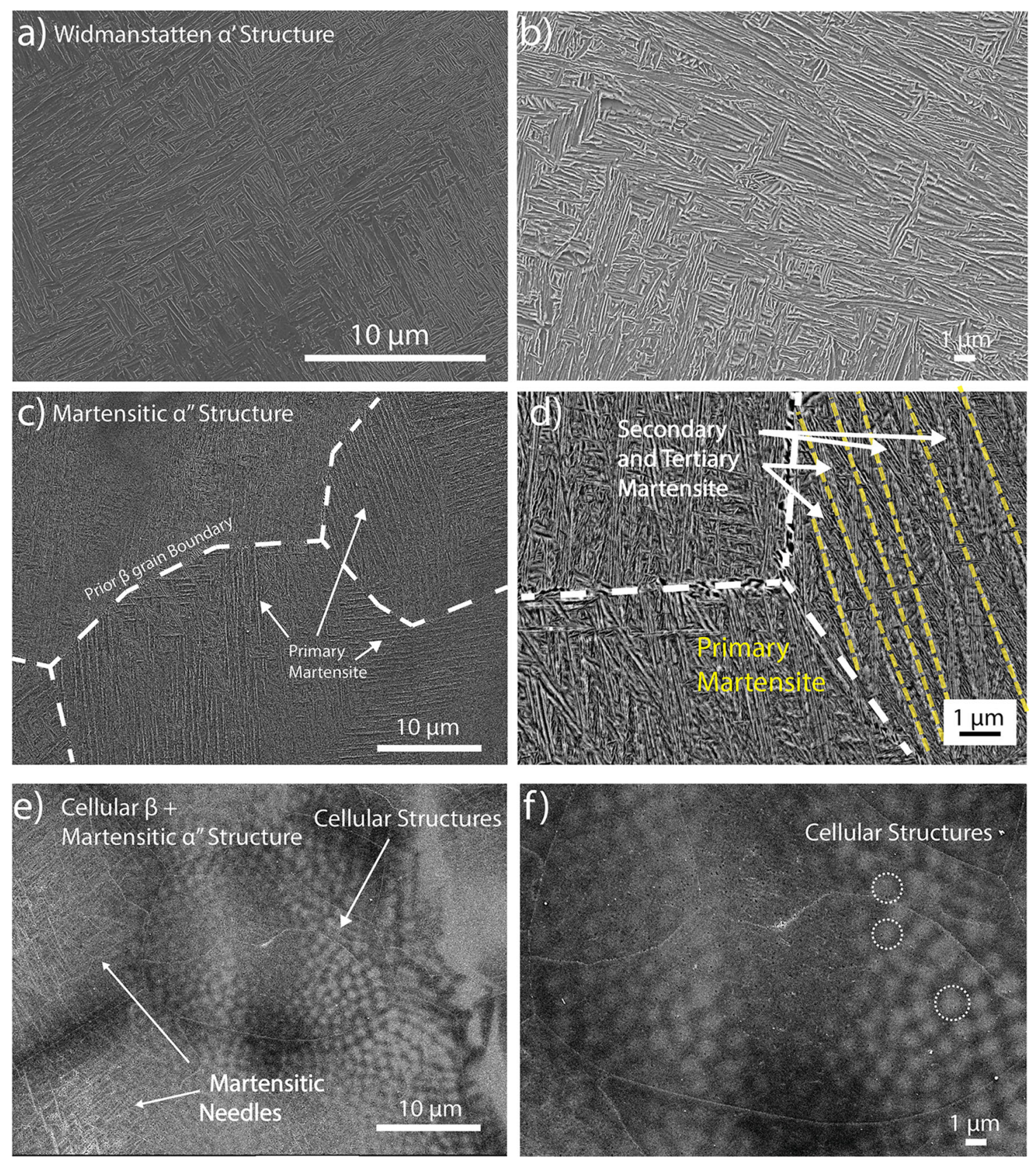

Fig. 9 SEM (Backscatter) micrographs (X-Y cross-sectional plane) of Ti-10Nb (a,b), Ti-20Nb (c,d) and Ti-30Nb (e,f) alloys, as-fabricated at an energy density of $230 \mathrm{~J} / \mathrm{mm}^{3}$

detected. Although the cooling rate was not directly measured, the presence of the martensite phase gives an indication of the high cooling rate of the SLM process. This assumption can be made, as this phase has been reported elsewhere, when a high cooling rate occurs (Ref 7,31). Other studies have measured the cooling rate of the SLM process, with P.A. Hooper (Ref 35) measuring the cooling rate in the range of $1 \mathrm{E} 5-1 \mathrm{E} 6{ }^{\circ} \mathrm{C} / \mathrm{s}$. A similar cooling rate would give rise to a martensitic microstructure similar to the one obtained in this study. The increased $\mathrm{Nb}$ content led to increased $\beta$ stabilisation and $\beta$ phase fraction, compared against the $\mathrm{Ti}-20 \mathrm{Nb}$ alloy. The dendritic formations are a result of the presence of large $\mathrm{Nb}$ (solute) content, and the rapid cooling of the SLM process. These two factors contribute to constitutional undercooling, destabilisation of the solidifica- tion front and the formation of dendritic structures within the larger prior $\beta$ grains. As shown by Dargusch et al. (Ref 36) these dendritic needles form in the build direction, which when viewed from the normal direction, as in Fig. 9f, are visible as a cellular structure. A result of the concentration of $\mathrm{Nb}$ within the initially solidifying dendritic structures, leaves the surroundings with a reduced $\mathrm{Nb}$ content. This leads to the dual $\alpha$ " and $\beta$ phase composition, with inner dendrites forming the $\beta$ phase, while the surrounding regions forming the $\alpha$ " phase due to the depleted $\mathrm{Nb}$ content and reduced $\beta$ stabilisation (Ref 19,22,3739). The reduced solute content in the Ti- $10 \mathrm{Nb}$ and Ti-20Nb alloys meant the solidification front was stable and planar, with no dendritic structures visible within the bulk of the alloys. However, some dendritic solidification was present in the Ti- 


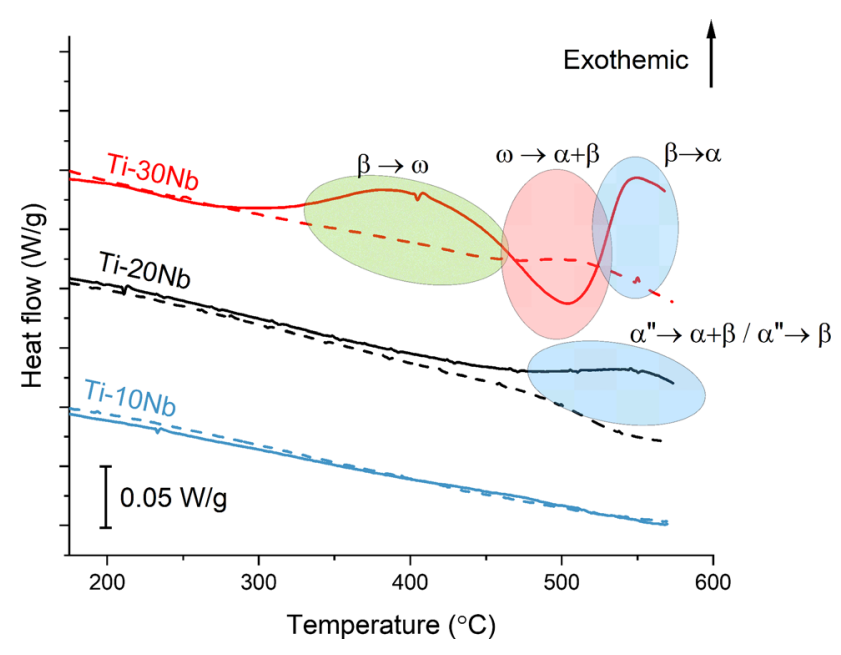

Fig. 10 DSC heating curves of the Ti-Nb alloys as-fabricated at an energy density of $230 \mathrm{~J} / \mathrm{mm}^{3}$ (dotted line represents 2 nd heating run)

$20 \mathrm{Nb}$ alloys in the areas of elevated $\mathrm{Nb}$ content surrounding un-alloyed $\mathrm{Nb}$ particles.

\subsection{Thermal Analysis}

Figure 10 shows the heating curves of Ti-(10-30) Nb compositions fabricated using $230 \mathrm{~J} / \mathrm{mm}^{3}$. The cooling curves of the sample composition are shown in Fig. 11. The dotted line is the 2 nd run of the same sample performed to assess the presence of metastable phases in the first thermal cycle. The Ti$10 \mathrm{Nb}$ alloys expressed no peaks related to the martensitic phase transformation in the temperature range, assessed during the heating run nor the cooling run. The low $\mathrm{Nb}$ content of this alloy results in an expected transformation temperature above the maximum temperature of the DSC equipment used. The martensitic transformation of $\mathrm{Ti}-10 \mathrm{Nb}$ is expected at around $713{ }^{\circ} \mathrm{C}$, above the scanned range (Ref 25). The Ti-20Nb alloy expressed an exothermic peak at the top of the heating curve from $470{ }^{\circ} \mathrm{C}$. This transformation matches exothermic peaks, linked to the martensitic $\alpha$ " phase transformations in similar compositions at similar temperatures seen elsewhere (Ref $31,40)$. However, it is unclear, if this transformation is related to $\alpha$ " to $\alpha+\beta$ or $\alpha$ " to $\beta$ dissolutions. During the second heating run this peak is not present, suggesting the metastable nature of the transformation, and confirming it is most likely associated with the $\alpha$ " dissolution. No peaks were identified in the cooling curve that could be linked to phase transformations. The Ti$30 \mathrm{Nb}$ alloy, fabricated at $230 \mathrm{~J} / \mathrm{mm}^{3}$, exhibited large variations in the heat flow during the heating run. An exothermic peak is present between 300 and $450{ }^{\circ} \mathrm{C}$, followed by the endothermic peak between 460 and $530{ }^{\circ} \mathrm{C}$, and finally an exothermic peak at $540{ }^{\circ} \mathrm{C}$. Bonisch et al. and Kent et al. linked this transformation to an isothermal $\omega$ phase transformation in similar compositions (Ref 41,42). The first exothermic peak is linked to the $\beta$ to $\omega$ transformation, the endothermic peak linked to the $\omega$ to $\alpha+\beta$ transformation, and the final exothermic peak being $\beta$ to $\alpha$ transformation. In addition, the heat flow moves to an endothermic peak above the max temperature of the DSC scan. This is likely the $\beta$ transus, matching the expected temperature based on the composition. In this composition, no $\alpha$ " to $\beta$ transformation can be detected, despite the $\alpha$ " phase being detected in the XRD patterns

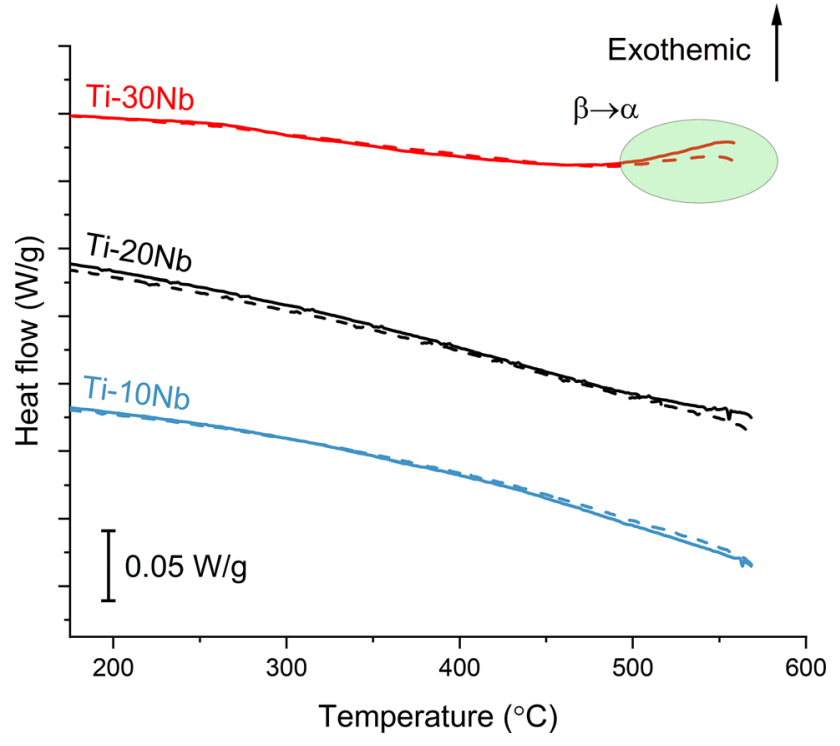

Fig. 11 DSC cooling curves of the Ti-Nb alloys as-fabricated at an energy density of $230 \mathrm{~J} / \mathrm{mm}^{3}$ (dotted line represents 2nd cooling run)

(Fig. 5) of the as-fabricated part. It is likely as the $\beta$ to $\omega$ transformation and $\alpha$ " to $\beta$ transformation occur at concurrent temperatures, therefore it is hard to distinguish these transformations and this peak contains both transformations. The cooling curve shows part of an exothermic transformation at the start, and is most likely linked to the $\beta$ to $\alpha$ transformations.

\subsection{Mechanical Properties}

3.6.1 Young's Modulus. Figure 12 shows the compressive stress-strain curves of the alloys loaded until yield. These compression tests were performed on samples with dimensions $12 \mathrm{~mm}$ in length and $6 \mathrm{~mm}$ in diameter. With increasing $\mathrm{Nb}$ content there is a change in yield behaviour, with a reduction in the sharpness of the yield points. This change corresponds with an increasing martensitic structure present within the alloy, $\alpha^{\prime}$ in Ti- $10 \mathrm{Nb}$ and $\alpha$ " in Ti-20Nb. This yield behaviour could be the result of micro-yielding caused by high local internal stress that resulted from the martensitic phase transformation (Ref 43). In addition, there is an increase in strain at yield with the addition of $\mathrm{Nb}$. A more defined yield point can be seen in Ti-30Nb alloys, as the $\alpha$ " phase fraction decreased with increasing $\mathrm{Nb}$ content.

The Young's Modulus (Fig. 13) decreased with increasing $\mathrm{Nb}$ content, reaching its lowest values of 61-65 $\mathrm{GPa}$ with the addition of $20 \mathrm{Nb}$, before increasing to $70-84 \mathrm{GPa}$, when the $\mathrm{Nb}$ content increases to $30 \mathrm{Nb}$. Young's Modulus values of the developed alloys follow a similar pattern to those fabricated using casting techniques, with the addition of $\mathrm{Nb}$ leading to an initial decrease in the Young's Modulus. A decrease with the addition of $20 \mathrm{Nb}$ fraction in SLM samples measured between 34 and $36 \mathrm{GPa}$. This trend follows those described in literature for cast samples, e.g. Lee et al. found that the modulus decreased by $30 \mathrm{GPa}$ with the formation of $\alpha$ " (Ref 7). A minimum has been suggested to be around Ti- $15 \mathrm{Nb}$, linked to the point, where the $\alpha$ phase loses its hexagonality, and starts to form the orthorhombic phase (Ref 5,44). Similar conclusions have been drawn by Wang et al. (Ref 24). The increased modulus of the Ti-30Nb samples is unexpected due the lower modulus of the $\beta$ phase, compared to the $\alpha$ " phase (Ref 45 ). 

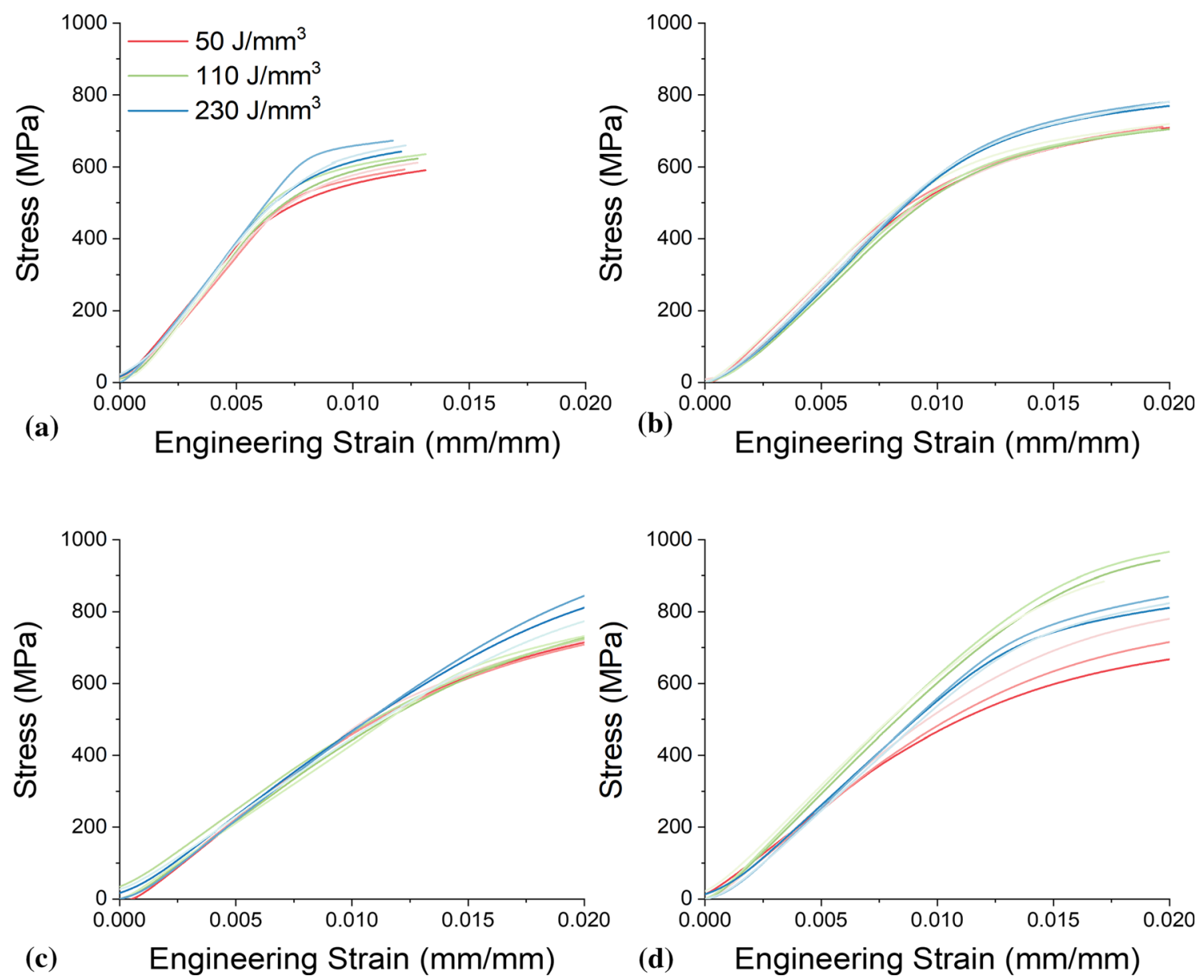

Fig. 12 Compressive Stress-Strain graphs for CP-Ti (a), Ti-10Nb (b), Ti-20Nb (c), and Ti-30Nb (d) alloys fabricated at the chosen energy densities

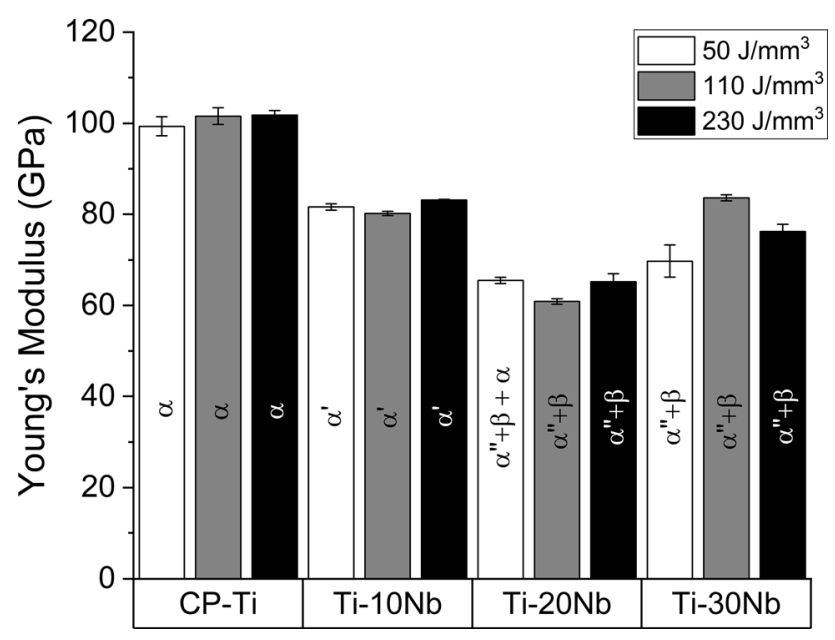

Fig. 13 Young's Moduli of the CP-Ti and Ti-Nb alloys fabricated at the chosen energy densities

However, the increase has been linked to the presence of the brittle $\omega$ phase, with similar increases in Moduli being found in cast samples and linked to the $\omega$ phase in literature (Ref 42,46). Therefore, the increase in the Young's Modulus cannot be associated with the increased $\beta$ phase fraction, and must be linked to the precipitation of the $\omega$ phase (Ref 7). However, its small size makes it hard to detect using x-ray diffraction (Ref 47). The $\omega$ phase can be formed either from rapid cooling (athermal), or upon ageing (isothermal), with both occurring at similar $\mathrm{Nb}$ contents (Ref 31 ). Therefore, the isothermal $\omega$ transformations detected in the DSC scans (Fig. 10) suggests the addition of $30 \mathrm{Nb}$ has the potential for athermal $\omega$ phase formation during the rapid cooling of the SLM process. This is also suggested by the increase in the Young's Modulus seen. However, the presence of the athermal $\omega$ phase in the asfabricated samples is not confirmed, and further investigations are needed.

The variation with energy density was also found to influence the Young's Modulus. In CP-Ti samples, the Young's Modulus increased from 99 to $102 \mathrm{GPa}$ with increasing energy density. This can be linked to the increased densification and reduction in porosity at higher energy densities. In the Ti-Nb alloys, as well as the reduced porosity, the variations in the Moduli can be the result from variations such in phases present, homogeneity, as well as the fraction of un-melted $\mathrm{Nb}$ particles. As all of these phenomena are influenced by the energy density and occur concurrently, the exact mechanism behind the variation with energy density, is yet to be isolated.

Table 3 shows a comparison between cast and SLM titanium alloys for biomedical applications extracted from literature against the alloys reporting the lowest Young's Modulus developed in this study. The Young's Modulus of the alloys developed in this study compare favourably to the un-alloyed 
Table 3 Comparison between mechanical properties of SLM and Cast titanium alloys developed for biomedical applications studied in literature and alloys developed in this study

\begin{tabular}{|c|c|c|c|c|}
\hline Composition, wt.\% & Method & Young's Modulus & Yield Strength & Reference \\
\hline CP-Ti & Cast & $100 \mathrm{GPa}$ & $240 \mathrm{MPa}$ & Geetha et al. (Ref 2) \\
\hline $\mathrm{Ti}-20 \mathrm{Nb}$ & Cast & $61 \mathrm{GPa}$ & $\ldots$ & Lee et al. (Ref 7) \\
\hline TNTZ(Ti-29Nb-13Ta-4.6Zr) & Cast & $63 \mathrm{GPa}$ & $\ldots$ & Niinomi et al. (Ref 49) \\
\hline $\mathrm{Ti}-38 \mathrm{Nb}$ & Cast & $56 \mathrm{GPa}$ & $850 \mathrm{MPa}$ & Guo et al. (Ref 50) \\
\hline $\mathrm{Ti}-42 \mathrm{Nb}$ & SLM & $61 \mathrm{GPa}$ & $674 \mathrm{MPa}$ & Schulze et al. (Ref 29$)$ \\
\hline $\mathrm{Ti}-26 \mathrm{Nb}$ & SLM & $70 \mathrm{GPa}$ & $\ldots$ & Fischer et al. (Ref 22) \\
\hline Ti-13Nb-13Zr & SLM & $65 \mathrm{GPa}$ & $794 \mathrm{MPa}$ & Zhou et al. (Ref 51) \\
\hline Ti-25Ta & SLM & $75 \mathrm{GPa}$ & $882 \mathrm{MPa}$ & Zhao et al. (Ref 37$)$ \\
\hline $\mathrm{Ti}-20 \mathrm{Nb}\left(110 \mathrm{~J} / \mathrm{mm}^{3}\right)$ & SLM & $61.0 \pm 0.6 \mathrm{GPa}$ & $675 \pm 29 \mathrm{MPa}$ & This study \\
\hline $\mathrm{Ti}-20 \mathrm{Nb}\left(230 \mathrm{~J} / \mathrm{mm}^{3}\right)$ & SLM & $65.2 \pm 1.8 \mathrm{GPa}$ & $769 \pm 36 \mathrm{MPa}$ & This study \\
\hline
\end{tabular}

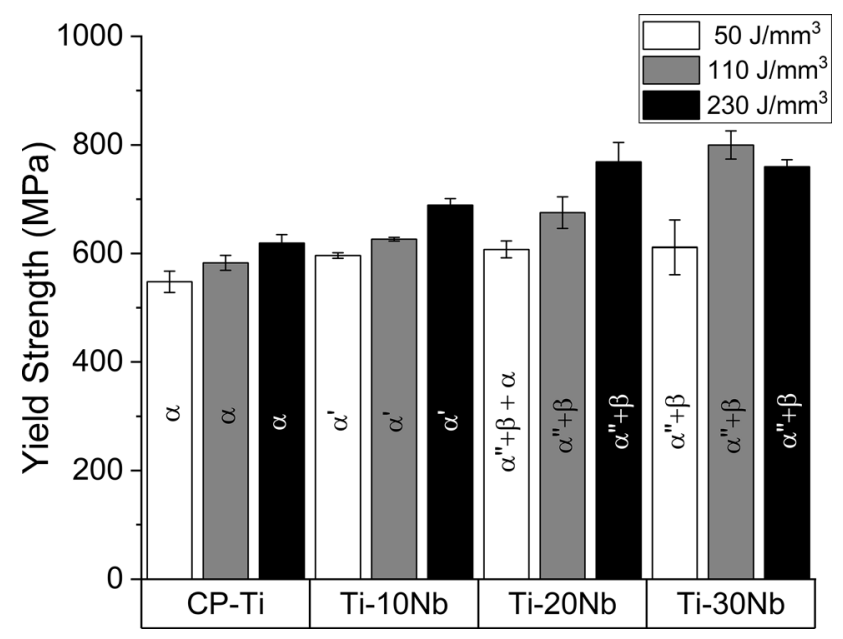

Fig. 14 Yield Strength of the CP-Ti and Ti-Nb alloys fabricated at the chosen energy densities

titanium (reduction of 34-36 GPa), and are comparable to the properties found in cast and SLM $\beta$-stabilised Ti alloys of similar compositions.

3.6.2 Yield Strength. The yield strength (Fig. 14) was found to increase with the addition of $\mathrm{Nb}$ and energy density. Increasing $\mathrm{Nb}$ content between 0 and $20 \mathrm{Nb}$, increased the yield strength, resulting from solid solution strengthening with the addition of $\mathrm{Nb}$ into the Ti matrix. Although studies on SLM manufactured $\mathrm{Ti}$ alloys are scarce, a similar effect has been reported with the introduction of $\beta$ stabilisers, using other fabrication techniques (Ref 7,48). Increasing the energy density in the Ti- $10 \mathrm{Nb}$ and $\mathrm{Ti}-20 \mathrm{Nb}$ also led to an increased yield strength, due to increased homogenisation, and therefore, increased solid solution strengthening effect. In addition, the extended $\beta$ stabilisation led to the stabilisation of the orthorhombic $\alpha$ " phase. Due to the increased dislocation density and small crystal spacing of the martensite phase, which hinders the motion of dislocations, increasing the fraction of this phase led to an increase in the yield strength. However, as indicated by the increase in yield strength in the un-alloyed $\mathrm{Ti}$, from 548 to $618 \mathrm{MPa}$, the reduction in void content and preferred orientation in the build direction (corresponding to the direction of loading during the test) also causes an increase in the yield strength. At Ti-30Nb there is a reduction in the yield strength from samples manufactured with $230 \mathrm{~J} / \mathrm{mm}^{3}$ compared to samples manufactured with $110 \mathrm{~J} / \mathrm{mm}^{3}$, from 800 to 760 $\mathrm{MPa}$. This is likely the result of increased homogenisation at the higher energy density, increasing the stabilisation of the $\beta$ phase. This leads to a reduction in the $\alpha$ " phase fraction, and a corresponding increase of the $\beta$ phase fraction. Therefore, the strengthening effect of the martensite phase is reduced and yield strength decreases. Similar findings are reported by Vrancken et al., with the introduction of $10 \mathrm{Mo}$ (wt.\%) into Ti$6 \mathrm{Al}-4 \mathrm{~V}$, resulting in the change from $\alpha$ to $\beta$ phases, and a corresponding reduction in yield strength (Ref 16$)$.

\section{Conclusions}

The effect of energy density and $\mathrm{Nb}$ content on $\mathrm{Ti}-\mathrm{Nb}$ alloys manufactured using SLM was investigated by studying their mechanical and microstructural properties. The results are summarised as follows:

(1) It was possible to achieve exemplars of Ti allotropes by increasing the amount of $\mathrm{Nb}$ in the alloy; Ti-10Nb processed at any of the energy densities displayed an a' phase. At $\mathrm{Ti}-20 \mathrm{Nb}$ and above $110 \mathrm{~J} / \mathrm{mm}^{3}$ orthorhombic $a$ " phase appeared. In Ti-30Nb fabricated at $230 \mathrm{~J} / \mathrm{mm}^{3}$, the martensite transformation was suppressed, and the alloy exhibited a primarily $\beta$ microstructure.

(2) Across all $\mathrm{Nb}$ content, increasing the energy density, reduced the presence of voids, and increased the homogenisation in the sample. The energy density of $230 \mathrm{~J} / \mathrm{mm}^{3}$ created a homogenised microstructure, showing a small number of un-melted $\mathrm{Nb}$ particles, and presenting low void content.

(3) The Ti-20Nb samples produced using $230 \mathrm{~J} / \mathrm{mm}^{3}$ displayed the largest strength-to-stiffness ratio amongst the entire set, with a Young's Modulus of $65.2 \pm 1.8 \mathrm{GPa}$ and a Yield Strength of $769 \pm 36 \mathrm{MPa}$, ascribed to the stabilisation of the fine-grained $\alpha$ " martensite, sufficient solid solution strengthening and adequate chemical homogenisation.

(4) This study demonstrates that the SLM process promotes in-situ alloying for the fabrication of $\mathrm{Ti}-\mathrm{Nb}$ alloys, which display a low Young's modulus, comparable to properties of samples manufactured via conventional 
methods, such as casting, and without the requirement for pre-alloyed powders. This represents a great advantage in the manufacture of low stiffness, high strength Ti alloys in a more simplified process.

\section{Acknowledgments}

The authors are grateful to the Wolfson School Doctoral Scholarship and the Engineering and Physical Sciences Research Council (grant No. EP/P027482/1) for financial support. The authors acknowledge use of the facilities and the assistance of Dr. Keith Yendall in the Loughborough Materials Characterisation Centre (Loughborough University).

\section{Open Access}

This article is licensed under a Creative Commons Attribution 4.0 International License, which permits use, sharing, adaptation, distribution and reproduction in any medium or format, as long as you give appropriate credit to the original author(s) and the source, provide a link to the Creative Commons licence, and indicate if changes were made. The images or other third party material in this article are included in the article's Creative Commons licence, unless indicated otherwise in a credit line to the material. If material is not included in the article's Creative Commons licence and your intended use is not permitted by statutory regulation or exceeds the permitted use, you will need to obtain permission directly from the copyright holder. To view a copy of this licence, visit http://creativecommons.org/licenses/by/4.0/.

\section{References}

1. J. Helsen and H. Jurgen (1998) Metals As Biomaterials

2. M. Geetha, A.K. Singh, R. Asokamani and A.K. Gogia, Ti Based Biomaterials, the Ultimate Choice for Orthopaedic Implants - A Review, Prog. Mater. Sci., 2009, 54(3), p 397-425

3. Y.-H. Hon, J.-Y. Wang and Y.-N. Pan, Composition/Phase Structure and Properties of Titanium-Niobium Alloys, Mater. Trans., 2003, 44(11), p 2384-2390

4. A. Biesiekierski, J. Wang, M. Abdel-Hady Gepreel and C. Wen, A New Look at Biomedical Ti-Based Shape Memory Alloys, Acta Biomater, 2012, 8(5), p 1661-1669

5. M. Bönisch, M. Calin, J. Van Humbeeck, W. Skrotzki and J. Eckert, Factors Influencing the Elastic Moduli, Reversible Strains and Hysteresis Loops in Martensitic Ti-Nb Alloys, Mater. Sci. Eng. C, 2015, 48, p 511-520

6. H. Matsuno, A. Yokoyama, F. Watari, M. Uo and T. Kawasaki, Biocompatibility and Osteogenesis of Refractory Metal Implants Titanium, Hafnium, Niobium, Tantalum and Rhenium, Biomaterials, 2001, 22(11), p 1253-1262

7. C.M. Lee, C.P. Ju and J.H. Chern Lin, Structure-Property Relationship of Cast Ti-Nb Alloys, J. Oral Rehabil., 2002, 29, p 314-322

8. D.C. Zhang, Y.F. Mao, Y.L. Li, J.J. Li, M. Yuan and J.G. Lin, Effect of Ternary Alloying Elements on Microstructure and Superelastictity of Ti-Nb Alloys, Mater. Sci. Eng. A, 2013, 559, p 706-710

9. W.S.W. Harun, M.S.I.N. Kamariah, N. Muhamad, S.A.C. Ghani, F. Ahmad and Z. Mohamed, A Review of Powder Additive Manufacturing Processes for Metallic Biomaterials, Powder Technol., 2018, 327, p 128-151

10. F. Trevisan, F. Calignano, A. Aversa, G. Marchese, M. Lombardi, S. Biamino, D. Ugues and D. Manfredi, Additive Manufacturing of Titanium Alloys in the Biomedical Field: Processes, Properties and Applications, J. Appl. Biomater. Funct. Mater., 2017, 16(2), p 57-67

11. M. Simonelli, Y.Y. Tse and C. Tuck, The Formation of $\alpha+\beta$ Microstructure in As-Fabricated Selective Laser Melting of Ti-6Al-4V, J. Mater. Res., 2014, 29(17), p 2028-2035
12. L. Thijs, F. Verhaeghe, T. Craeghs, J. Van Humbeeck and J.P. Kruth, A Study of the Microstructural Evolution during Selective Laser Melting of Ti-6Al-4V, Acta Mater., 2010, 58(9), p 3303-3312

13. J.Y. Cho, W. Xu, M. Brandt and M. Qian, Selective Laser MeltingFabricated Ti-6Al-4V Alloy: Microstructural Inhomogeneity, Consequent Variations in Elastic Modulus and Implications, Opt. Laser Technol., 2018, 111, p 664-670

14. I. Yadroitsev, P. Krakhmalev and I. Yadroitsava, Titanium Alloys Manufactured by In Situ Alloying During Laser Powder Bed Fusion, Jom, 2017, 69(12), p 2725-2730

15. M. Simonelli, N.T. Aboulkhair, P. Cohen, J.W. Murray, A.T. Clare, C. Tuck and R.J.M. Hague, A Comparison of Ti-6Al-4V in-Situ Alloying in Selective Laser Melting Using Simply-Mixed and Satellited Powder Blend Feedstocks, Mater. Charact., 2018, 143, p 118-126

16. B. Vrancken, L. Thijs, J.P. Kruth and J. Van Humbeeck, Microstructure and Mechanical Properties of a Novel $\beta$ Titanium Metallic Composite by Selective Laser Melting, Acta Mater., 2014, 68, p 150-158

17. A. Hattal, T. Chauveau, M. Djemai, J.J. Fouchet, B. Bacroix and G. Dirras, Effect of Nano-Yttria Stabilized Zirconia Addition on the Microstructure and Mechanical Properties of Ti6A14V Parts Manufactured by Selective Laser Melting, Mater. Des., 2019, 180, p 1-9

18. E. Chlebus, B. Kuźnicka, R. Dziedzic and T. Kurzynowski, Titanium Alloyed with Rhenium by Selective Laser Melting, Mater. Sci. Eng. A, 2015, 620, p 155-163

19. F.E. Wiria, S.L. Sing, and W.Y. Yeong, Selective Laser Melting of Novel Titanium-Tantalum Alloy As Orthopedic Biomaterial, Solid Free. Fabr. 2017 Proc. 28th Annu. Int., p 2389-2397 (2017)

20. S.L. Sing, W.Y. Yeong and F.E. Wiria, Selective Laser Melting of Titanium Alloy with $50 \mathrm{Wt} \%$ Tantalum: Microstructure and Mechanical Properties, J. Alloys Compd., 2016, 660, p 461-470

21. N. Kang, Y. Li, X. Lin, E. Feng and W. Huang, Microstructure and Tensile Properties of Ti-Mo Alloys Manufactured via Using Laser Powder Bed Fusion, J. Alloys Compd., 2019, 771, p 877-884

22. M. Fischer, D. Joguet, G. Robin, L. Peltier and P. Laheurte, In Situ Elaboration of a Binary Ti-26Nb Alloy by Selective Laser Melting of Elemental Titanium and Niobium Mixed Powders, Mater. Sci. Eng. C, 2016, 62, p 852-859

23. W. Chen, C. Chen, X. Zi, X. Cheng, X. Zhang, Y.C. Lin and K. Zhou, Controlling the Microstructure and Mechanical Properties of a Metastable $\beta$ Titanium Alloy by Selective Laser Melting, Mater. Sci. Eng. A, 2018, 726, p 240-250

24. Q. Wang, C. Han, T. Choma, Q. Wei, C. Yan, B. Song and Y. Shi, Effect of $\mathrm{Nb}$ Content on Microstructure, Property and in Vitro ApatiteForming Capability of Ti-Nb Alloys Fabricated via Selective Laser Melting, Mater. Des., 2017, 126, p 268-277

25. S. Neelakantan, P.E.J. Rivera-Díaz-del-Castillo and S. van der Zwaag, Prediction of the Martensite Start Temperature for $\beta$ Titanium Alloys as a Function of Composition, Scr. Mater., 2009, 60(8), p 611-614

26. G. Lutjering and J.C. Williams, "Titanium," 2nd ed., Springer, 2007

27. D.D. Gu, W. Meiners, K. Wissenbach and R. Poprawe, Laser Additive Manufacturing of Metallic Components: Materials, Processes and Mechanisms, Int. Mater. Rev., 2012, 57(3), p 133-164

28. H. Attar, S. Ehtemam-Haghighi, D. Kent, X. Wu and M.S. Dargusch, Comparative Study of Commercially Pure Titanium Produced by Laser Engineered Net Shaping, Selective Laser Melting and Casting Processes, Mater. Sci. Eng. A, 2017, 705, p 385-393

29. C. Schulze, M. Weinmann, C. Schweigel, O. Keßler and R. Bader, Mechanical Properties of a Newly Additive Manufactured Implant Material Based on Ti-42Nb, Materials (Basel), 2018, 11(1), p 13-16

30. "Standard Test Methods of Compression Testing of Metallic Materials at Room Temperature, E9," Annual Book of ASTM Standards, 2018

31. M. Bönisch, M. Calin, T. Waitz, A. Panigrahi, M. Zehetbauer, A. Gebert, W. Skrotzki and J. Eckert, Thermal Stability and Phase Transformations of Martensitic Ti-Nb Alloys, Sci. Technol. Adv. Mater., 2013, 14(5), p 055004

32. H.Y. Kim, Y. Ikehara, J.I. Kim, H. Hosoda and S. Miyazaki, Martensitic Transformation, Shape Memory Effect and Superelasticity of Ti-Nb Binary Alloys, Acta Mater, 2006, 54(9), p 2419-2429

33. M.S. Dargusch, G. Wang, D. Kent, M. Bermingham, J. Venezuela, J.E. Frith, Z. Yu, S. Yu and Z. Shi, Comparison of the Microstructure and Biocorrosion Properties of Additively Manufactured and Conventionally Fabricated near $\beta$ Ti-25Nb-3Zr-3Mo-2Sn Alloy, ACS Biomater. Sci. Eng., 2019, 5(11), p 5844-5856 
34. J. Yang, H. Yu, J. Yin, M. Gao, Z. Wang and X. Zeng, Formation and Control of Martensite in Ti-6Al-4V Alloy Produced by Selective Laser Melting, Mater. Des., 2016, 108, p 308-318

35. P.A. Hooper, Melt Pool Temperature and Cooling Rates in Laser Powder Bed Fusion, Addit. Manuf., 2018, 22(May), p 548-559

36. H. Attar, S. Ehtemam-Haghighi, D. Kent and M.S. Dargusch, Recent Developments and Opportunities in Additive Manufacturing of Titanium-Based Matrix Composites: A Review, Int. J. Mach. Tools Manuf., 2018, 133, p 85-102

37. D. Zhao, C. Han, Y. Li, J. Li, K. Zhou, Q. Wei, J. Liu and Y. Shi, Improvement on Mechanical Properties and Corrosion Resistance of Titanium-Tantalum Alloys in-Situ Fabricated via Selective Laser Melting, J. Alloys Compd., 2019, 804, p 288-298

38. K. Zhuravleva, M. Bönisch, K.G. Prashanth, U. Hempel, A. Helth, T. Gemming, M. Calin, S. Scudino, L. Schultz, J. Eckert and A. Gebert, Production of Porous $\beta$-Type Ti-40Nb Alloy for Biomedical Applications: Comparison of Selective Laser Melting and Hot Pressing, Materials (Basel), 2013, 6(12), p 5700-5712

39. L. Thijs, K. Kempen, J.P. Kruth and J. Van Humbeeck, Fine-Structured Aluminium Products with Controllable Texture by Selective Laser Melting of Pre-Alloyed AlSi10Mg Powder, Acta Mater., 2013, 61(5), p 1809-1819

40. A. Josephine Prabha, S. Raju, B. Jeyaganesh, A.K. Rai, M. Behera, M. Vijayalakshmi, G. Paneerselvam and I. Johnson, Thermodynamics of $\alpha^{\prime \prime} \rightarrow \beta$ Phase Transformation and Heat Capacity Measurements in Ti-15 at\% Nb Alloy, Phys. B Condens. Matter., 2011, 406(22), p 4200 4209

41. D. Kent, S. Pas, S. Zhu, G. Wang and M.S. Dargusch, Thermal Analysis of Precipitation Reactions in a Ti-25Nb-3Mo-3Zr-2Sn Alloy, Appl. Phys. A Mater. Sci. Process., 2012, 107(4), p 835-841

42. M. Bönisch, A. Panigrahi, M. Calin, T. Waitz, M. Zehetbauer, W. Skrotzki and J. Eckert, Thermal Stability and Latent Heat of Nb-rich Martensitic Ti-Nb Alloys, J. Alloys Compd., 2017, 697, p 300-309
43. B. Hutchinson, D. Lindell and M. Barnett, Yielding Behaviour of Martensite in Steel, ISIJ Int., 2015, 55(5), p 1114-1122

44. Y. Mantani and M. Tajima, Effect of Ageing on Internal Friction and Elastic Modulus of Ti-Nb Alloys, Mater. Sci. Eng. A, 2006, 442, p 409-413

45. J. Sun, Q. Yao, H. Xing and W.Y. Guo, Elastic Properties of $\beta, \alpha^{\prime \prime}$ and $\omega$ Metastable Phases in Ti-Nb Alloy from First-Principles, J. Phys. Condens. Matter., 2007, 19(48), p 486215

46. P.E.L. Moraes, R.J. Contieri, E.S.N. Lopes, A. Robin and R. Caram, Effects of Sn Addition on the Microstructure, Mechanical Properties and Corrosion Behavior of Ti-Nb-Sn Alloys, Mater. Charact., 2014, 96, p 273-281

47. E.L. Pang, E.J. Pickering, S.I. Baik, D.N. Seidman and N.G. Jones, The Effect of Zirconium on the Omega Phase in Ti-24Nb-[0-8]Zr (at.\%) Alloys, Acta Mater, 2018, 153, p 62-70

48. M.K. Han, J.Y. Kim, M.J. Hwang, H.J. Song and Y.J. Park, Effect of $\mathrm{Nb}$ on the Microstructure, Mechanical Properties, Corrosion Behavior, and Cytotoxicity of Ti-Nb Alloys, Materials (Basel), 2015, 8(9), p 5986-6003

49. M. Niinomi, Y. Liu, M. Nakai, H. Liu and H. Li, Biomedical Titanium Alloys with Young's Moduli Close to that of Cortical Bone, Regen. Biomater, 2016, 3(3), p 173-185

50. S. Guo, J. Zhang, X. Cheng and X. Zhao, A Metastable $\beta$-Type Ti-Nb Binary Alloy with Low Modulus and High Strength, J. Alloys Compd., 2015, 644, p 411-415

51. L. Zhou, T. Yuan, R. Li, J. Tang, M. Wang and F. Mei, Anisotropic Mechanical Behavior of Biomedical Ti-13Nb-13Zr Alloy Manufactured by Selective Laser Melting, J. Alloys Compd., 2018, 762, p 289-300

Publisher's Note Springer Nature remains neutral with regard to jurisdictional claims in published maps and institutional affiliations. 